\title{
3D numerical simulation of upflow bubbling fluidized bed in opaque tube under high flux solar heating
}

\author{
Hadrien Benoit ${ }^{\mathrm{a}}$, Renaud Ansart ${ }^{\mathrm{b}}$, Hervé Neau ${ }^{\mathrm{c}}$, Pablo Garcia Triñanes ${ }^{\mathrm{d}}$, \\ Gilles Flamant ${ }^{\mathrm{b}}$, Olivier Simonin ${ }^{\mathrm{c}}$ \\ ${ }^{a}$ PROMES-CNRS 7 rue du four solaire, 66120 Font-Romeu Odeillo, France \\ ${ }^{b}$ Laboratoire de Génie Chimique, Université de Toulouse, CNRS, Toulouse, France \\ ${ }^{c}$ Institut de Mécanique des Fluides de Toulouse (IMFT), Université de Toulouse, CNRS, \\ Toulouse, France \\ ${ }^{d}$ Wolfson Centre for Bulk Solids Handling Technology, Faculty of Engineering and \\ Science, University of Greenwich, United Kingdom
}

\begin{abstract}
Solid particles can be used as a heat transfer medium in concentrated solar power plants to operate at higher temperature and achieve higher heat conversion efficiency than using the current solar Heat Transfer Fluids (HTF) that only work below $600{ }^{\circ} \mathrm{C}$. Among various particle circulation concepts, the Dense Particle Suspension (DPS) flow in tubes, also called Upflow Bubbling Fluidized Bed (UBFB), was studied in the frame of the CSP2 FP7 European project. The DPS capacity to extract heat from a tube absorber exposed to concentrated solar radiation was demonstrated and the first values of the tube wall-to-DPS heat transfer coefficient were measured. A stable outlet temperature of $750{ }^{\circ} \mathrm{C}$ was reached with a metallic tube, and a particle reflux in the near tube wall region was evidenced. In this paper, the UBFB behavior is studied using the multiphase flow code NEPTUNE_CFD.
\end{abstract}

\footnotetext{
* Corresponding author.

Email address: renaud.ansart@ensiacet.fr, Tel: +33 534323701 (Renaud Ansart)
} 
Hydrodynamics of SiC Geldart A-type particles and heat transfer imposed by a thermal flux at the wall are coupled in 3D unsteady numerical simulations. The convective/diffusive heat transfer between the gas and dispersed phase, and the inter-particle radiative transfer (Rosseland approximation) are accounted for. Simulations and experiments are compared here and the temperature influence on the DPS flow is analyzed.

Keywords: particle solar receiver, gas-particle flow, heat transfer fluid, euler-euler model, 3D numerical simulation

\section{Introduction}

Concentrated Solar Power (CSP) plants convert solar thermal energy into electricity replacing process heat provided by the combustion boiler in classical power plants by a solar receiver that absorbs concentrated solar radiation to heat a Heat Transfer Fluid (HTF). Such solar power plants offer the key advantage of producing electricity on-demand thanks to a Thermal Energy Storage (TES) stage. State-of-the-art solar power tower plants use nitrate molten salt as HTF and TES material. Maximum operation temperature of the $\mathrm{HTF}$ is $560{ }^{\circ} \mathrm{C}$ and the corresponding steam thermodynamic cycle efficiency is about $42 \%$. Targeted cycle efficiency for the next generation of solar towers is above $50 \%$ which implies that they should operate at temperatures higher than $650^{\circ} \mathrm{C} .{ }^{1}$ Consequently, research and development efforts are oriented towards three main targets: to develop new HTF and TES, and to define new thermodynamic cycles. The best option for HTF and TES is choosing a fluid/material that can be used for both functions. Concerning high efficiency cycle, supercritical $\mathrm{CO}_{2}$ and combined cycles are 
potential options. Fluidized ceramic particles allow creating liquid like flows (Dense Particle Suspension, DPS) while being able to withstand high temperatures, below to the solid sintering temperature $\left(1400{ }^{\circ} \mathrm{C}\right.$ for $\mathrm{SiC}$ particles $)$. Moreover, particles are interesting TES materials because they can be easily stored and energy can be extracted from the hot storage vessels using fluidized beds. ${ }^{2}$ Various particle receiver conceptual designs are currently under development worldwide. ${ }^{3}$ We propose the fluidized particle in tube solution that is detailed hereafter.

Experiments were conducted first on a cold mock-up, ${ }^{4,5}$ then with a single-tube experimental receiver set at the focus of the CNRS $1 \mathrm{MW}$ solar furnace in Odeillo. ${ }^{6}$ A stable outlet temperature of $750{ }^{\circ} \mathrm{C}$ was reached with a metallic tube, and a particle reflux in the near tube wall region was evidenced. ${ }^{7}$ The experimental wall-to-DPS global heat transfer coefficients over the irradiated tube height ranged from 400 to $1,100 \mathrm{~W} / \mathrm{m}^{2} . \mathrm{K}$.

The particle movement and solids concentration were also studied by using Positron Emission Particle Tracking $(\mathrm{PEPT})^{8}$ and local heat transfer coefficients measured using small probes employing electrical resistance heating. 9

3D numerical simulations of the single-tube solar receiver setup were conducted in order to better understand the particle flow and the heat transfer mechanisms inside the absorber tube. The Eulerian-Eulerian approach was chosen in regard of the very large number of particles $\left(>10^{10}\right)$. Indeed, this number of particles is clearly impossible to compute using an Euler-Lagrange approach therefore the NEPTUNE_CFD massively parallel computational code was used to simulate the DPS circulation at ambient temperature. ${ }^{10}$ 
The numerical results were compared to those obtained on the cold mock-up and to those of Positron Emission Particle Tracking (PEPT) experiments conducted by CSP2 project partners. ${ }^{8}$ The solid recirculation evidenced by the DPS temperature distribution in the absorber tube during on-sun experiments was observed in both simulations and PEPT experiments. This shows the capability of the code to reproduce this peculiar flow pattern by making use of the implemented mathematical models.

This paper presents simulations of the DPS flow in a heated tube aiming to reproduce on-sun experiments on a single-tube solar receiver. First, the experimental setup is described. After that, the simulation parameters are detailed: geometry and mesh, phases properties, mathematical models, boundary conditions. Just after that the simulation procedure is explained. Then, the numerical and experimental results are compared at the level of the linear pressure loss and temperature to validate the model. Finally, the influence of the temperature on the DPS flow is analyzed.

\section{Single-tube DPS solar receiver experimental setup}

This setup and the results obtained during on-sun experimental campaigns have already been the object of two journal publications. ${ }^{6,7}$ Therefore it will only be briefly explained in this section. The principle of the DPS solar receiver is to create an upward flow of solid particles from a bottom Fluidized Bed (FB), called Dispenser Fluidized Bed (DiFB) that delivers to a vertical tube exposed to concentrated solar radiation instantaneously heating the tube wall. The heat is then transmitted to the particles circulating inside that finally flow out of the tube into a collector FB. The DPS is obtained by 
fluidizing the particles in the DiFB with air injected through a sintered metal plate at the bottom of the chamber to reach a state of bubbling fluidized bed. The air flow at the DiFB outlet is controlled by an electronic valve. The closure of this valve leads to a freeboard pressure increase and subsequently the DPS moves upwards within the tube so that the hydrostatic pressure drop compensates the pressure increase. The circulation is successfully achieved by stabilizing the DPS level in the tube at the tube outlet height and injecting more solid particles in the DiFB. To maintain the pressure equilibrium, the same solid flow rate injected in the DiFB has to exit the system and therefore flow out of the tube.

The experimental setup was equipped with thermocouples that measured the DPS temperature and allowed to determine experimentally the heat transferred to the particles.

\section{Simulation parameters}

\section{Geometry and mesh}

The simulated geometry, that was confined to the DiFB and the absorber tube, is shown in Figure 1. The DiFB could not be removed from the simulation because experimental results showed that what happens at the tube inlet has a direct impact on the DPS flow inside the tube. The DiFB has a horizontal section area of $0.02 \mathrm{~m}^{2}, 0.4 \mathrm{~m}$ height and it is equipped with a lateral solid entrance and an air evacuation at the top. The total height of the tube is $2.06 \mathrm{~m}$ high and $0.034 \mathrm{~m}$ in diameter. Its inlet is set $0.1 \mathrm{~m}$ above the bottom of the chamber (fluidization plate). An aeration injection is located at $0.57 \mathrm{~m}$ from its inlet. The geometry dimensions replicate those of the cold 
mock-up. The computational mesh contained 1,650,000 hexahedra, $1.5 \mathrm{~mm}$ high and around $1.2 \mathrm{~mm}$ wide cells.

We chose to keep the same geometry as previously used for simulations without heating to be able to compare both numerical studies. It slightly differed from the geometry of the experimental solar receiver. The geometry was divided into two parts: The DiFB and the tube submitted to the solar radiation. The DiFB section was larger in the experiments $\left(0.16 \mathrm{~m}^{2}\right.$ instead of $\left.0.04 \mathrm{~m}^{2}\right)$. Boissiere $(2015)^{5}$ has shown that the flow inside the tube is not dependent of the DiFB dimensions if the DiFB is well fluidized. The tube diameter for the experiments is $36 \mathrm{~mm}$ instead of $34 \mathrm{~mm}$ for the simulations. However, the two tube diameters are very close and the authors believe that this difference does not have a significant effect on the hydrodynamics. The tube inlet was set $0.1 \mathrm{~m}$ above the fluidization plate whereas in the experiments it was $+0.04 \mathrm{~m}$. Finally, the aeration injection was set $0.57 \mathrm{~m}$ above the tube inlet in the simulations instead of $0.3 \mathrm{~m}$ in the on-sun experiments. 


\section{Phases properties}

The shape of the $\mathrm{SiC}$ particles used in this study was very irregular together with a broad size distribution $(d 10=44 \mu \mathrm{m}, d 50=70 \mu \mathrm{m}, d 90=130$ $\mu \mathrm{m})$. The equivalent mean Sauter diameter was $63.9 \mu \mathrm{m}$. Due to the shape distribution of the particles, the bed expansion was under-estimated by the model used here when the imposed diameter was $64 \mu \mathrm{m}$. Therefore the particle diameter was set to $40 \mu \mathrm{m}$ to obtain the same numerical bed expansion as the one measured experimentally, while considering perfectly spherical particles. See ${ }^{10}$ for further details.

The $\mathrm{SiC}$ particles properties used in the simulations are displayed in Table 1. They were calculated from the data given in. ${ }^{11}$ NEPTUNE_CFD heat transfer equations are written with the phases' specific enthalpies, therefore the variables used in these equations (specific heat capacity and temperature) must be calculated from the specific enthalpy. The protocol used to obtain the value is as follows. First, the particles' specific heat capacity $C_{p, p}$ was expressed as a polynomial of the temperature. Then, it was integrated to determine the particle's specific enthalpy $H_{p}$ as a function of the temperature, with the enthalpy reference $(0 \mathrm{~J} / \mathrm{kg})$ set at $20{ }^{\circ} \mathrm{C}(=293.15 \mathrm{~K})$. Finally, the temperature and the specific heat capacity were expressed as polynomials of the specific enthalpy in $[\mathrm{J} / \mathrm{kg}]$.

The air properties are also indicated in Table 1 . The density was calculated using the perfect gas law. The polynomials for the specific heat capacity, dynamic viscosity and thermal diffusivity were determined from tabulated data given in Perry's Chemical Engineers' Handbook. ${ }^{12}$ The same treatment as for the particle properties was applied to obtain polynomials of 
the specific enthalpy in $[\mathrm{J} / \mathrm{kg}]$.

The validity of the polynomials was checked for both phases: after a temperature is chosen, the specific enthalpy at this temperature is calculated, then the temperature is re-calculated from the specific enthalpy. For the temperature range $273-1000 \mathrm{~K}$, the maximum deviation was $0.3 \%$. 


\section{Mathematical models}

The 3D numerical simulations of the experimental DPS solar receiver were carried out using an Eulerian n-fluid modeling approach for turbulent and polydispersed fluid-particle flows, ${ }^{13}, 14$ which was developed and implemented by the Fluid Mechanics Institute of Toulouse (in French: Institut de Mécanique des Fluides de Toulouse - IMFT) in NEPTUNE_CFD code. This multiphase flow software uses the finite-volume method, with unstructured meshes, to run parallel calculations, ${ }^{15}$ with a predictor-corrector method for the equation numerical simulation. ${ }^{16}$ It is developed by a consortium between Commission for Atomic Energy (in French: Commissariat à l'Énergie Atomique - CEA), Électricité de France (EDF), Radioprotection and $\mathrm{Nu}$ clear Safety Institute (in French: Institut de Radioprotection et de Sûreté Nucléaire - IRSN) and AREVA in the frame of the NEPTUNE project.

The Eulerian n-fluid approach used here is a hybrid method ${ }^{17}$ in which the transport equations are derived by ensemble averaging conditioned by the phase presence for the continuous gaseous phase and by use of the kinetic theory of granular flows supplemented by fluid effects for the dispersed phase. The momentum transfer between gas and particle phases is modeled using the drag law of Wen and $\mathrm{Yu},{ }^{18}$ limited by the Ergun equation ${ }^{19}$ for dense flows. ${ }^{20}$ The collisional particle stress tensor is derived in the frame of the kinetic theory of granular media. ${ }^{21}$ In the present study the gas flow equations are treated considering a laminar regime because the gas Reynolds stress tensor in the momentum equation is neglected compared to the drag term. For the solid phase, a transport equation for the particle random kinetic energy, $q_{p}^{2}$, is solved. The quasi-static granular flow zones are taken into account in 
the particle stress tensor by the additional frictional stress tensor. ${ }^{22}$ All the equations are detailed in. ${ }^{15}$

The enthalpy of each phase in the UBFB satisfies the transport equation:

$$
\frac{\partial}{\partial t}\left(\alpha_{k} \rho_{k} H_{k}\right)+\frac{\partial}{\partial x_{j}}\left(\alpha_{k} \rho_{k} H_{k} U_{k, j}\right)=\frac{\partial}{\partial x_{j}}\left(\alpha_{k} \rho_{k} K_{k} \frac{\partial H_{k}}{\partial x_{j}}\right)+\sum_{m \neq k} \Pi_{k \rightarrow m}
$$

where $H_{k}, \rho_{k}$ and $\alpha_{k}$ are the specific enthalpy, the density and the volume fraction of phase $k$ respectively.

Assuming that the heat exchanged by contact during interparticle collision is negligible, modeled heat transfer to the particle is only accounting for 1) heat exchange by the gas phase, 2) radiative heat transfer between the particles and 3) transport by random velocity fluctuations (kinetic diffusion) summarized by:

- The convection/diffusion heat transfer $\Pi_{g \rightarrow p}$ between the gaseous phase and the particles occurring with a characteristic time scale $\tau_{g p}^{T}$ such as

$$
\Pi_{g \rightarrow p}=-\Pi_{p \rightarrow g}=\alpha_{p} \rho_{p} C_{p_{p}} \frac{1}{\tau_{g p}^{T}}\left(T_{p}-T_{g}\right), \text { with } \frac{1}{\tau_{g p}^{T}}=\frac{6 \lambda_{g}}{\rho_{p} C_{p_{p}}} \frac{\langle N u\rangle_{p}}{d_{p}^{2}}
$$

where $\lambda_{g}$ is the thermal conductivity of the gaseous phase. $\left\langle N u_{p}\right\rangle=$ $2+0.55 \operatorname{Re}_{p}^{1 / 2} \operatorname{Pr}^{1 / 323}$ (correlation for dilute flow) represents the Nusselt number of the particle phase while $\operatorname{Pr}=\nu_{g} / K_{g}^{l}$ denotes the Prandtl number. $C_{p_{k}}$ is the specific heat of the $k^{\text {th }}$ phase in the fluidized bed. Correlations for dense flow such as Gunn ${ }^{24}$ could be used but the characteristic time given by Ranz and Marshall ${ }^{23}$ is already very small compared to the other mechanisms so the particle and gas temperatures 
are almost equal in all the simulations. Thus, an increase of the value of Nusselt number by using Gunn's correlation will have no measurable effect on the simulation.

- For the particle phase, the diffusivity coefficient is obtained as $K_{p}=$ $K_{p}^{t}+K_{p}^{r}$, where $K_{p}^{t}$ and $K_{p}^{r}$ are the contributions due to the transport of the enthalpy by the random velocity fluctuations and to the radiative heat transfer between the particles, respectively. Due to the high extinction coefficient of the dense suspension, ${ }^{25}$ the medium can be considered opaque for thickness larger than $3 l_{R} \approx 1 \mathrm{~mm}$. The absorption length $l_{R}$ is small compared to the variation length scale of the DPS temperature. So the Rosseland approximation is valid to represent the particle-particle radiative transfer in the fluidized bed, except maybe in the very-near wall region, a few particle diameter from the wall. Assuming that the radiation between particles in dense fluidized beds takes place in the frame of the Rosseland approximation through a diffusion mechanism, Konan et al. ${ }^{13}$ wrote the radiative flux in the alumina particle enthalpy equation as proportional to the temperature gradient with a radiative thermal diffusion coefficient given by

$$
K_{p}^{r}=\frac{32 \sigma}{9 \alpha_{p}} \frac{d_{p} T_{p}^{3}}{\rho_{p} C_{p_{p}} \varepsilon_{p}^{0}}
$$

in which $\sigma$ denotes the Stefan-Boltzmann constant and $T_{p}$ the temperature of the particles and $\varepsilon_{p}^{0}$ is particle emissivity assumed equal to 1 in our case of study. $K_{p}^{t}$ is expressed by Lavieville et al.. ${ }^{26}$ 


$$
K_{p}^{t}=\left(\tau_{g p}^{F} \frac{2}{3} q_{p}^{2}\right)\left(1+\frac{2}{3} \frac{\tau_{g p}^{F}}{\tau_{p}^{c}}\right)^{-1}
$$

where $\tau_{g p}^{F}$ is the gas-particle relaxation timescale, $q_{p}^{2}$ is the random kinetic particle energy and $\tau_{p}^{c}$ is the collision timescale. ${ }^{15}$

- For the gas phase, the diffusivity coefficient is obtained as $K_{g}=K_{g}^{t}+$ $K_{g}^{l}$, where $K_{g}^{t}$ and $K_{g}^{l}$ are the contributions to the transport of the enthalpy due to the gas turbulent velocity and to the laminar diffusivity, respectively. In the present study we consider $K_{g}^{t}=0$.

The heat transfer between the wall and the two phase mixture is due to the sum of the wall-particles radiative transfer and to the gas conduction. Therefore, due to the large solid volume fraction, the major radiative heat exchange with the wall takes place within a distance of a few particle diameters. $^{27,28}$ In addition, the gas conduction at the wall is imposed $T_{g}=T_{w}$ and leads to a strong non equilibrium situation between the two phases $\left(T_{g} \neq T_{p}\right)$. But this effect is removed rapidly when leaving the wall due to the very strong inter-phase heat transfer effect.

Thus few particle diameters from the wall, the gas and the particle should have nearly the same temperature and the heat transport is dominated by the solid phase contribution due to the large thermal inertia $\left(\alpha_{p} \rho_{p} C_{p_{p}}>>\right.$ $\left.\alpha_{g} \rho_{g} C_{p_{g}}\right)$. Then the first computing point being sufficiently far from the wall $\left(\Delta X_{\text {cell }}>>d_{p}\right)$, we may assume that the major part of the flux exchanged with the wall is transported by the solid.

In practice a Neuman enthalpy boundary condition and a flux enthalpy boundary condition are imposed for gas and solid phases respectively as 
described below.

\section{Boundary conditions}

\section{Flow conditions}

The geometry was composed by 3 inlet boundaries. The fluidization plate through which the air was injected at a constant mass flow rate corresponded to an air superficial velocity close to $2 U_{m f}$. The air was injected at the DiFB temperature. This boundary was seen as a wall by the solid phase. The lateral solid injection, where the solid mass flow rate, was imposed with an 0.5 particle volume fraction and an extremely low air mass flow rate. Both phases were injected at the DiFB temperature. The aeration injection, situated $0.57 \mathrm{~m}$ above the tube inlet, where the air mass flow rate was set to reproduce the experimental aeration mass flux (= superficial mass flow rate). The aeration air was injected at $100{ }^{\circ} \mathrm{C}$.

The geometry had two free outlets: one on the DiFB ceiling, through which only air passed (the circulating solid fraction was negligible) and the other one at the top of the tube. A pressure loss was imposed on the DiFB outlet to control the freeboard pressure rather than a flow rate condition. This choice was made to reproduce the behavior of the pressure control valve used in the experiments. The desired solid flux through the tube was obtained by adjusting the pressure loss coefficient, which is similar to changing the valve setting. The outlet pressure was the atmospheric pressure $P_{a t m}=$ 101,325 Pa.

The wall boundary condition was a no-slip condition ${ }^{29}$ for both gas and particles. 


\section{Heat conditions}

The heat flux density condition applied was varied along the tube height to be as close as possible to the solar experiments. From the tube inlet $(0.1 \mathrm{~m})$ to the cavity inlet $(1.1 \mathrm{~m})$, the experimental tube was insulated. Therefore, an adiabatic condition was applied in the simulations. From the cavity inlet $(1.1 \mathrm{~m})$ to its outlet $(1.6 \mathrm{~m})$, the tube was exposed to concentrated solar radiation, so a positive heat flux density was applied (denoted as "Heating" in Figure 1). After the irradiated cavity, the tube passed through the cavity insulation. In this zone $(1.6 \mathrm{~m}$ to $1.7 \mathrm{~m})$ an adiabatic condition was imposed. Above $1.7 \mathrm{~m}$, the tube was not insulated at all, which led to high heat losses. This was represented by a negative heat flux density with a high loss from $1.7 \mathrm{~m}$ to $2 \mathrm{~m}$ and a lower one between $2 \mathrm{~m}$ and $2.1 \mathrm{~m}$ since the heat loss is higher when the temperature is higher ("Cooling 1" and "Cooling 2" in Figure 1, respectively).

The model cannot predict wall-to-bed heat transfer and thus requires a heat flux boundary condition at the wall. A uniform heat flux density was imposed at the tube wall in the heating region. In that regard, there is a significant difference between experiments and simulations. Indeed, during the experiments, the tube had one side directly exposed to the concentrated solar flux, whereas the opposite side only received the radiation reflected and emitted by the cavity. This cavity is made of insulating material with an 0.65 reflectivity to solar radiation that helps making the incoming radiative flux around the tube more uniform to some extent. The approximation of uniform heat flux was used due to the lack of another option, since the reflected and reemitted fluxes coming from the cavity were not measured. The total heat rate 
transferred to the DPS during experiments was estimated from the enthalpy balance of the solid phase considering the inlet and outlet of the system. Then, the averaged solar heat flux transferred to the DPS was obtained by dividing the total heat rate by the internal surface area of the irradiated part of the tube. This heat flux estimation was used in the simulation as a heat flux boundary condition in the heating region (Figure 1). However, using the experimental estimation of the heat flux led to an underestimation of the outlet temperature. It may be due to the uniform heat flux imposed or more probably to the overestimation of the particle recirculation. Hence, we chose to increase the heat flux to match outlet temperatures between the numerical predictions and the experimental measurement. Therefore, this value was dynamically adjusted to obtain temperature matching with the experimental measurement at the cavity outlet. We noticed that this adjustment method leads to an increase of between $20 \%$ and $40 \%$ of the imposed heat flux at the wall with respect to the initial estimation for the HQ case and Ref case respectively.

The boundary conditions of all the simulated cases are given in Table 2 . 


\section{Simulation procedure}

The calculations were conducted with 140 cores. The simulations began with a transitory period during which the control parameters, that are the pressure loss coefficient at the DiFB outlet and the heat flux densities, were adapted. Their influences on the temperature and solid flux in the tube are intertwined. On the one hand, increasing (decreasing) the pressure loss coefficient, which corresponds to a valve closing (opening), decreased (increased) the air flow rate passing through the pressure control valve (outlet of the DiFB) and therefore increased (decreased) the air flow through the tube. More (less) air going into the tube means more (less) solid carried up and an increased (decreased) solid flux. This solid flux modification, for given heat flux densities, induced temperature changes. On the other hand, modifying

the heat flux densities had an effect on the temperature distribution along the tube height. Since the temperature affects the air density and velocity, the DPS density is also impacted. A DPS density variation means a hydrostatic pressure variation, which leads to a changed air flow repartition between valve and tube that affects the solid flux going up the tube. Due to these coupled phenomena, the adjustments had to be done simultaneously for both control parameters, to finally obtain the experimental case conditions. These applied pressure loss coefficient and heat flux density inputs are not directly related to the experimental measurements that are the pressure, the temperatures and the solid mass flow rate. The numerical results are compared to the values measured experimentally in Table 3. Once the parameters were set correctly, the system converged towards a stable state with a constant solid mass in the geometry and a proper temperature distribution. 
The duration of the transitory regime, including the period to find the right parameters and the stabilization period, was at least $200 \mathrm{~s}$.

Even in a stable regime, the DPS flow was unsteady, which means that instantaneous characteristics were constantly changing. The regime is called stable because the time-averaged characteristics are constant after 150s.

To illustrate the unsteady flow, Figure 2 shows an instantaneous solid velocity field in the tube, for the Ref case, between 1.3 and $1.4 \mathrm{~m}, 720 \mathrm{~s}$ after the beginning of the simulation. The tube vertical slice is colored by the magnitude of the particle velocity. It can be seen that the particles are going up in some zones, down in some others, and that their velocities range from 0 to $0.5 \mathrm{~m} / \mathrm{s}$. Figure 3 illustrates the result obtained after a timeaveraged duration of $150 \mathrm{~s}$. The recirculation is evidenced by the averaged solid velocity positive in the center and negative close to the wall. 
Comparison between simulations and experiments 
The results of simulations and experiments are compared in Table 3. The DiFB pressure control allowed to work at solid fluxes almost identical to those of the selected experimental points with a $1.1 \%$ maximum absolute relative error. The linear pressure drop, which is directly linked to the hydrostatic pressure drop caused by the particle weight in the column, was well reproduced for the Ref and $\mathrm{HQ}$ cases (relative error $<3 \%$ ).

It must be noted that, in the DPS, the gas and solid have nearly the same temperature. $^{30}$ The temperature at the inlet of the irradiated cavity in the center of the tube $T_{i, c e n t e r}$ was overestimated by simulations. This is due to the overestimation of the solid recirculation. ${ }^{10}$ Indeed, if the downward flux is overestimated, more hot particles flow down below the irradiated cavity and preheat the particles by mixing before they reach the cavity inlet. The temperature at the cavity outlet in the tube center $T_{o, c e n t e r}$ was well reproduced for the Ref and HQ cases (absolute relative error $<3.5 \%$ ) thanks to the heat flux density condition adaptation. The temperature is well reproduced at $2 \mathrm{~m}$ which is normal since the heat flux conditions were set to respect the enthalpy balance over the whole tube length.

The temperature overestimation at the cavity inlet and underestimation at the cavity outlet were the most significant deviations for the HT case with the lowest solid flux. Contrarily, the HQ case was impacted the least by the overestimation of the recirculation. This is due to its impact effect on the solid flux. Indeed, when the average particle residence time in the tube is reduced, there is less mixing between upward and downward particle fluxes. 


\section{Numerical results: Temperature influence on DPS flow}

The analysis of the results focuses now on the impact of the temperature on the DPS flow characteristics. Only the HQ case and Ref case are shown here since the results were badly reproduced in the HT case.

\section{Temperature vertical profile}

Figure 4 and Figure 5 present the simulated time-averaged temperature profiles at the center of the tube and a distance $5 \mathrm{~mm}$ away from the tube wall along the tube height and the experimental temperatures for the Ref case and HQ case, respectively. For the Ref case, we clearly see the impact of the recirculation overestimation at the cavity inlet where the temperature simulated is far above the experimental one. Moreover, the temperature increase starts before the aeration which means that hot particles are flowing downward even below the aeration injection. At the cavity outlet, the temperature given by the simulation is lower than the one measured. But the maximum temperature in the simulation is seen $0.15 \mathrm{~m}$ below the cavity outlet. For the HQ case, the temperature is well reproduced at the cavity outlet at the tube center $(804 \mathrm{~K})$ but it is overestimated at the cavity inlet (684 $\mathrm{K}$ instead of $630 \mathrm{~K}$ ). The temperature increases from the aeration injection height to just below the cavity outlet and then decreases until it stabilizes at $2 \mathrm{~m}$. The shape of this profile is caused by the wall heat flux density condition with a downward shift induced by the recirculation (the temperature starts going up below the cavity inlet and reaches the maximum just below

the cavity outlet). In both cases, it can be noticed that the temperature difference between the tube center and the close to the wall is much lower 
for the simulations than for the experiments (Ref case: $10 \mathrm{~K}$ instead of $65 \mathrm{~K}$ - HQ case: $8 \mathrm{~K}$ instead of $78 \mathrm{~K}$ ). This could be caused by an overestimation of the particle mixing between the wall and tube center. 
Air velocity radial profile

Figure 6 presents the time-averaged gas vertical velocity $u_{g}, z$ radial profiles for the Ref and HQ cases respectively at 4 positions along the tube height (i.e. $0.5 \mathrm{~m}, 1.1 \mathrm{~m}, 1.6 \mathrm{~m}$ and $2 \mathrm{~m}$ ). These positions are below the aeration, at the inlet of the irradiated zone, at the outlet of the irradiated zone and above the irradiated zone, respectively. The first issue to notice is that the air velocity is positive in the center and negative near the wall. This is due to the particle recirculation. The velocity before the aeration is obviously lower than after because of the air mass flow rate provoked by the aeration. Moreover, we can appreciate that the velocity value is lower at 1.1 than regions above at $1.6 \mathrm{~m}$ and $2 \mathrm{~m}$. This is due to the air density decreasing with the pressure decrease and with the temperature increase. From 1.6 to $2 \mathrm{~m}$, the velocity decreases, while the pressure decreases, because the temperature is higher at $1.6 \mathrm{~m}$ than at $2 \mathrm{~m}$, making the air density lower. The velocity close to the wall is greater (in the downward direction) for the Ref case than for the HQ case while the velocity in the center almost does not change from one case to another. This is in agreement with the recirculation being greater in the Ref case. 
Solid volume fraction radial profile and bubbles influence

Figures 7 presents the time-averaged solid volume fraction $\alpha_{p}$ radial profiles for the Ref and $\mathrm{HQ}$ cases respectively at 4 positions along the tube height: $0.5 \mathrm{~m}, 1.1 \mathrm{~m}, 1.6 \mathrm{~m}$ and $2 \mathrm{~m}$. It can be seen that $\alpha_{p}$ is higher at $0.5 \mathrm{~m}$, below the aeration located at $0.67 \mathrm{~m}$. The aeration purpose was to help the solid circulation, and $\alpha_{p}$ was lowered as a consequence of the air flow increase. This effect is well reproduced by the simulations. The profiles show that the volume fraction is higher close to the tube wall than at the center. This difference is markedly higher above the aeration. This is due to the bubbles circulating in the central zone of the tube. When the height equals $2 \mathrm{~m}, \alpha_{p}$ is equal to 0.23 for the Ref case and 0.26 for the HQ case at the center of the tube and it is $26 \%$ higher at the wall. We can also observe that it is higher at $1.1 \mathrm{~m}$ than above because the pressure is higher and the temperature lower, therefore the air velocity is lower. This means that the temperature, through its influence on the air density, impacts the solid volume fraction. 
Figure 8 depicts the solid volume fraction time-variance radial profiles for the Ref and HQ cases. This parameter characterizes the gas bubbles in the suspension that provoke great variations of the solid volume fraction. The time-variance of $\alpha_{p}$ is much lower at $0.5 \mathrm{~m}$ than above due to the aeration (at $0.67 \mathrm{~m}$ ) which increases the air flow rate and therefore increases the bubble size and frequency. The time-variance is the highest at $1.6 \mathrm{~m}$, same as for the air velocity. This indicates a direct link between the air velocity and the bubbles size and frequency. Above the aeration, the time-variance of $\alpha_{p}$ increases from the tube center to $3 \mathrm{~mm}$ from the wall and then decreases to reach its minimum at the wall. This profile shape can be explained by the combination of the bubbles passage and the $\alpha_{p}$ profile shape. There is practically no solid in the bubbles. As a consequence, their passage creates lower variations of $\alpha_{p}$ in the zones where $\alpha_{p}$ is low than in the zones of high solid volume fraction. Therefore, from the center to $3 \mathrm{~mm}$ from the wall, the time-variance of $\alpha_{p}$ increases as does $\alpha_{p}$. The bubbles circulate predominantly in the center of the tube. Hence, in the zone close to the wall region, their influence decreases and the time-variance of $\alpha_{p}$ decreases. 


\section{Solid flux radial profile}

Figures 9a and 9b present the solid flux $G_{p}$ radial profiles for the Ref and HQ cases respectively. The recirculation is clearly visible with $G_{p}$ being positive in the center and negative close to the wall. The recirculation ratio, defined as the ratio of descending solid flux over ascending solid flux, is much higher above the aeration, where the air flow rate is increased, than below. The circulation is clearly visible with $G_{p}$ being positive in the center and negative close to the wall.

It reaches a maximum value at $1.6 \mathrm{~m}$ where the air velocity is the highest due to the temperature influence. Therefore it can be said that there is a direct link between the air velocity and the solid recirculation. For a given solid flux, the higher the air velocity, the higher the recirculation. At $1.6 \mathrm{~m}$, the recirculation ratio is $83 \%$ in the Ref case and $64 \%$ in the HQ case. It is worth mentioning that these values are overestimated as showed by the comparison between experimental and simulated temperatures. However, it is confirmed that the higher the solid flux, the lower the recirculation. Moreover we can see that the recirculation zone (zone with a negative solid mass flux) is $4 \mathrm{~mm}$ thick for the entire tube height. 


\section{Particle velocity time-variance and random kinetic energy}

Figure 10 presents the particle vertical velocity time-variance radial profiles, and Figure 11 those of the particle radial velocity time-variance, for the Ref and HQ cases. The flow is clearly anisotropic with higher velocity timevariance in the vertical direction than in radial direction. Both time-variance are higher above the aeration than below. The profiles have a shape similar to those of the solid volume fraction time-variance with higher values in the center than at the wall. It was previously explained that the $\alpha_{p}$ time-variance profiles shape is caused by the bubbles passing. Therefore, it can be said that the bubbles are also responsible for the variations of the solid vertical and radial velocity. The $\left\langle u_{p, r}^{\prime} u_{p, r}^{\prime}>\right.$ time-variance fall occurs closer to the tube center, and the values at the wall are lower relatively to the values at the center. This is due to the wall effect that hinders the horizontal movement of the particles. For both $<u_{p, z}^{\prime} u_{p, z}^{\prime}>$ and $<u_{p, r}^{\prime} u_{p, r}^{\prime}>$ time-variances, it is observed that they are higher at $1.1 \mathrm{~m}$ than at $2 \mathrm{~m}$ in the Ref case, and lower in the HQ case. Moreover, the highest values are reached at $1.6 \mathrm{~m}$ and the differences between the values at $1.1 \mathrm{~m}$ and $1.6 \mathrm{~m}$ are greater in the HQ case than in the Ref case. This is linked to the temperature overestimation at the cavity inlet $(1.1 \mathrm{~m})$ which is greater in the Ref case than in the HQ case. For the Ref case, the temperature is higher at $1.1 \mathrm{~m}$ than at $2 \mathrm{~m}$, and the temperature difference between $1.1 \mathrm{~m}$ and $1.6 \mathrm{~m}$ is lower than for the HQ case (see Figures 4 and 5). When the temperature rises, the air velocity in-

creases, the bubbles circulate faster and the axial and radial particle mixing is intensified. 
The random kinetic energy of particles $q_{p}^{2}\left(=1 / 2\left\langle u_{p, i}^{\prime} u_{p, i}^{\prime}\right\rangle\right)$ represents the particle agitation at the microscopic level. Figure 12 presents the $q_{p}^{2}$ radial profiles for the Ref and HQ cases. It shows that the agitation is higher close to the wall than in the central zone of the tube. The heat transfer inside the suspension is due to two mechanisms: the particle diffusion linked to $q_{p}^{2}$, and the collective particle movement related to $\left\langle u_{p, r}^{\prime} u_{p, r}^{\prime}\right\rangle$. The time-variance of the computed velocity $<u_{p, r}^{\prime} u_{p, r}^{\prime}>$ is more than 10 times higher than $q_{p}^{2}$ at the wall and $10^{4}$ times higher in the central zone. Therefore, for the DPS flow in tube, the heat transfer from the wall to the center is due to the particle's collective movement. 


\section{Discussion}

In the studied case, we have seen that the temperature strongly impacts the air velocity through the density variation along the tube height. As a consequence, the solid volume fraction and the recirculation that depends on the air velocity are affected by the temperature. This influence is combined with that of the pressure.

This result will be useful when planning for the system scaling-up. Indeed, in industrial applications, the absorber tubes will be much longer (probably $8 \mathrm{~m}$ ) which means that the temperature raise, pressure loss and induced air velocity increase will be much higher. To keep the air velocity more or less constant over the tube height and prevent the detrimental effect to heat transfer plug-flow regime from appearing at high air velocity, it will be necessary to install air evacuations (with sintered metal filters to stop particles) to lower the air mass flow rate while the temperature goes up and the density goes down.

The tube length increment should not create other complications since the height itself does not impact the DPS flow (the recirculation zone width is constant over the tube height).

\section{Conclusion}

The 3D numerical study of the experimental DPS solar receiver was performed using the NEPTUNE_CFD numerical code. A uniform heat flux density condition over the absorber tube circumference was applied. The model reproduced the experimental results to some extent but slight differences were noted in some cases. The increment of the temperature before 
the heated zone due to the downward solid mass flux near the wall is well predicted. However, this effect is over estimated since the solid back-mixing is unrealistic.

The numerical results put in evidence the impact of the temperature on the DPS flow through its influence on the air density. The higher the temperature, the lower the solid volume fraction and the more intense the recirculation. It means that for industrial applications with lengthy absorber tubes, it could be necessary to compensate the air density decrease with the temperature increase and pressure reduction by evacuating a fraction of the air flow to maintain the air velocity constant.

The particle vertical and radial velocities time-variances were found to be provoked by the bubbles and directly related to the air velocity. The higher the air velocity, the higher the bubble influence and the higher the time-variances. The particle velocity variances represent the particle's collective movement while the random kinetic energy of particles characterizes the particle diffusion at the microscopic level. The simulations showed that the particle radial velocity time-variance was far greater than the random kinetic energy of particles, which indicates that the heat transfer from the tube wall to the tube center is due to the particle's collective movement. Moreover, it is noteworthy that the velocity variances are anisotropic (higher in vertical direction than in radial direction).

Several possibilities are currently being explored to improve the agreement between simulations and experiments. The major expected improvement is related to the hydrodynamic modeling. The mesh should be further refined specially in the radial direction. Alternative model for particle- 
particle friction and non-sphericity will be evaluated. The particle size distribution could be described by a polydispersed approach. Additionally, further studies may concern the modeling of wall-to-DPS heat exchange to account for the non uniform solar heating. Finally, we should consider other approaches for modeling wall-to-bed suspension conduction such as proposed by. $31,32,33$

\section{Acknowledgments}

This work was developed in the frame of the CSP2 European project. The authors acknowledge the European Commission for co-funding the "CSP2" Project - Concentrated Solar Power in Particles - (FP7, Project N 282 932). This work was granted access to the HPC resources of CALMIP under the allocation P1132 and CINES under the allocation gct6938 made by GENCI.

\section{List of Figures}

1 Diagram describing the simulated geometry. . . . . . . . . . 40

2 Instantaneous solid velocity vectors and solid velocity magnitude field in background at $\mathrm{t}=720 \mathrm{~s}$, in the tube region between 1.3 and $1.4 \mathrm{~m}$ (Ref case). . . . . . . . . . . . . 41

3 Time-averaged solid velocity vectors and solid vertical velocity field in background, in the tube region between 1.3 and $1.4 \mathrm{~m}$ (Ref case). . . . . . . . . . . . . . . . . 42

4 Simulated vertical time-averaged temperature profiles and experimental temperatures at the center of the tube and $5 \mathrm{~mm}$ from the tube wall (Ref case). . . . . . . . . . . . . . 43 
5 Simulated vertical time-averaged temperature profiles and experimental temperatures at the center of the tube and $5 \mathrm{~mm}$ from the tube wall (HQ case). . . . . . . . . . . . . . . . 44

6 Time-averaged gas vertical velocity radial profiles. . . . . . . . 45

7 Time-averaged solid volume fraction radial profiles. . . . . . . 46

8 Solid volume fraction time-variance radial profiles. . . . . . . . 47

9 Time-averaged solid mass flux radial profiles . . . . . . . . . 48

10 Particle vertical velocity time-variance radial profiles. . . . . . 49

11 Particle radial velocity time-variance radial profiles. . . . . . . 50

12 Radial profiles of time-averaged random kinetic energy of particles radial profiles. . . . . . . . . . . . . . . . . . 51

\section{Literature cited}

${ }^{1}$ M. Mehos, C. Turchi, J. Vidal, M. Wagner, Z. Ma, Concentrating solar power gen3 demonstration roadmap, Technical Report NREL/TP-550067464 .

${ }^{2}$ F. Gomez-Garcia, D. Gauthier, G. Flamant, Design and performance of a multistage fluidized bed heat exchanger for particle-receiver solar power plants with storage, Applied Energy 190 (2017) 510-523, 10.1016/j.apenergy.2016.12.140.

${ }^{3} \mathrm{C}$. Ho, A review of high-temperature particle receivers for concentrating solar power, Applied Thermal Engineering 109 (2016) 958-969.

${ }^{4}$ B. Boissière, R. Ansart, D. Gauthier, G. Flamant, M. Hemati, Experimental hydrodynamic study of gas-particle dense suspension upward flow for 
applications as new heat transfer and storage fluid, Canadian Journal of Chemical Engineering 93 (2015) 317-330.

${ }^{5}$ B. Boissière, Étude hydrodynamique et thermique d'un nouveau concept de récepteur solaire à suspensions denses gaz-particules (Hydrodynamic and thermal study of a new concept of solar receiver using dense gas-particle suspensions), Ph.D. thesis, Institut National Polytechnique de Toulouse (INP Toulouse) (2015).

${ }^{6}$ G. Flamant, D. Gauthier, H. Benoit, J.-L. Sans, R. Garcia, B. Boissière, R. Ansart, M. Hemati, Dense suspension of solid particles as a new heat transfer fluid for concentrated solar thermal applications: On-sun proof of concept, Chemical Engineering Science 102 (2013) 567-576.

${ }^{7}$ H. Benoit, I. P. López, D. Gauthier, J.-L. Sans, G. Flamant, On-sun demonstration of a $750 \mathrm{C}$ heat transfer fluid for concentrating solar systems: Dense particle suspension in tube, Solar Energy 118 (2015) 622-633.

${ }^{8}$ P. García-Triñanes, J. Seville, B. Boissière, R. Ansart, T. Leadbeater, D. Parker, Hydrodynamics and particle motion in upward flowing dense particle suspensions: Application in solar receivers, Chemical Engineering Science 146 (2016) 346-356.

${ }^{9}$ P. García-Triñanes, J. Seville, R. Ansart, H. Benoit, T. Leadbeater, D. Parker, Particle motion and heat transfer in an upward-flowing dense particle suspension: application in solar receivers, Chemical Engineering Science 177 (2018) 313-322. 
${ }^{10}$ R. Ansart, P. García-Triñanes, B. Boissière, H. Benoit, J. P. Seville, O. Simonin, Dense gas-particle suspension upward flow used as heat transfer fluid in solar receiver: Pept experiments and 3d numerical simulations, Powder Technology 307 (2017) 25-36.

${ }^{11}$ R. Munro, Material Properties of a Sintered alpha-SiC, Journal of Physical and Chemical Reference Data 26 (1997) 1195-1203.

${ }^{12}$ D. Green, R. Perry, Perry's Chemical Engineers' Handbook, 8th Edition, McGraw-Hill Professional, 2008, (Section 2, Thermodynamic Properties).

${ }^{13}$ N. Konan, H. Neau, O. Simonin, M. Dupoizat, T. Le Goaziou, CFD prediction of uranium tetrafluoride particle fluorination in fluidized bed pilot, Proceedings of AIChE Annual Meeting, Nashville, USA (2009).

${ }^{14}$ F. Fotovat, R. Ansart, M. Hemati, O. Simonin, J. Chaouki, Sand-assisted fluidization of large cylindrical and spherical biomass particles: Experiments and simulation, Chemical Engineering Science 126 (2015) 543-559.

${ }^{15}$ Z. Hamidouche, E. Masi, P. Fede, R. Ansart, H. Neau, M. Hemati, O. Simonin, Numerical simulation of multiphase reactive flows, Advances in Chemical Engineering.

${ }^{16}$ N. Méchitoua, M. Boucker, J. Laviéville, S. Pigny, G. Serre, An unstructured finite volume solver for two phase water/vapour flows based on an elliptic oriented fractional step method, Proceedings of NURETH 10, Seoul, South Korea.

${ }^{17}$ S. Morioka, T. Nakajima, Modeling of gas and solid particles two-phase 
flow and application to fluidized bed, Journal of Theoretical and Applied Mechanics 6 (1) (1987) 77-88.

${ }^{18} \mathrm{C}$. Wen, Y. Yu, Mechanics of fluidization, Chemical Engineering Symposium Series 62 (1965) 100-111.

${ }^{19}$ S. Ergun, Fluid flow through packed columns, Chemical Engineering Progress 48.

${ }^{20}$ A. Gobin, H. Neau, O. Simonin, J.-R. Llinas, V. Reiling, J.-L. Sélo, Fluid dynamic numerical simulation of a gas phase polymerization reactor, International Journal for Numerical Methods in Fluids 43 (2003) 1199-1220.

${ }^{21}$ A. Boëlle, G. Balzer, O. Simonin, Second-order prediction of the particlephase stress tensor of inelastic spheres in simple shear dense suspensions, In Gas-Particle flows, ASME FED 28 (1995) 9-18.

${ }^{22}$ A. Srivastava, S. Sundaresan, Analysis of a frictional kinetic model for gas/particle flows, Powder Technology 129 (2003) 72-85.

${ }^{23}$ W. Ranz, W. Marshall, et al., Evaporation from drops, Chem. Eng. Prog 48 (3) (1952) 141-146.

${ }^{24}$ D. Gunn, Transfer of heat or mass to particles in fixed and fluidised beds, International Journal of Heat and Mass Transfer 21 (4) (1978) 467-476.

${ }^{25} \mathrm{C}$. Tien, Thermal radiation in packed and fluidized beds, Journal of Heat transfer 110 (4b) (1988) 1230-1242. 
${ }^{26}$ J. Laviéville, E. Deutsch, O. Simonin, Large eddy simulation of interactions between colliding particles and a homogeneous isotropic turbulence field, ASME-PUBLICATIONS-FED 228 (1995) 347-358.

${ }^{27}$ G. Flamant, N. Fatah, Y. Flitris, Wall-to-bed heat transfer in gassolid fluidized beds: Prediction of heat transfer regimes, Powder technology 69 (3) (1992) 223-230.

${ }^{28}$ J. Marti, A. Haselbacher, A. Steinfeld, A numerical investigation of gasparticle suspensions as heat transfer media for high-temperature concentrated solar power, International Journal of Heat and Mass Transfer 90 (2015) 1056-1070.

${ }^{29}$ P. Fede, O. Simonin, A. Ingram, 3D numerical simulation of a labscale pressurized dense fluidized bed focussing on the effect of the particle-particle restitution coefficient and particle-wall boundary conditions, Chemical Engineering Science 142 (2016) 215-235.

${ }^{30}$ J. Baeyens, W. Goossens, Some aspects of heat transfer between a vertical wall and a gas fluidized bed, Powder Technology 8 (1973) 91-96.

${ }^{31}$ M. Syamlal, D. Gidaspow, Hydrodynamics of fluidization: prediction of wall to bed heat transfer coefficients, AIChE Journal 31 (1) (1985) 127135.

${ }^{32}$ J. Kuipers, W. Prins, W. P. M. Van Swaaij, Numerical calculation of wall-to-bed heat-transfer coefficients in gas-fluidized beds, AIChE Journal 38 (7) (1992) 1079-1091. 
${ }^{33}$ A. Morris, S. Pannala, Z. Ma, C. Hrenya, A conductive heat transfer model for particle flows over immersed surfaces, International Journal of Heat and Mass Transfer 89 (2015) 1277-1289. 
List of Figures 


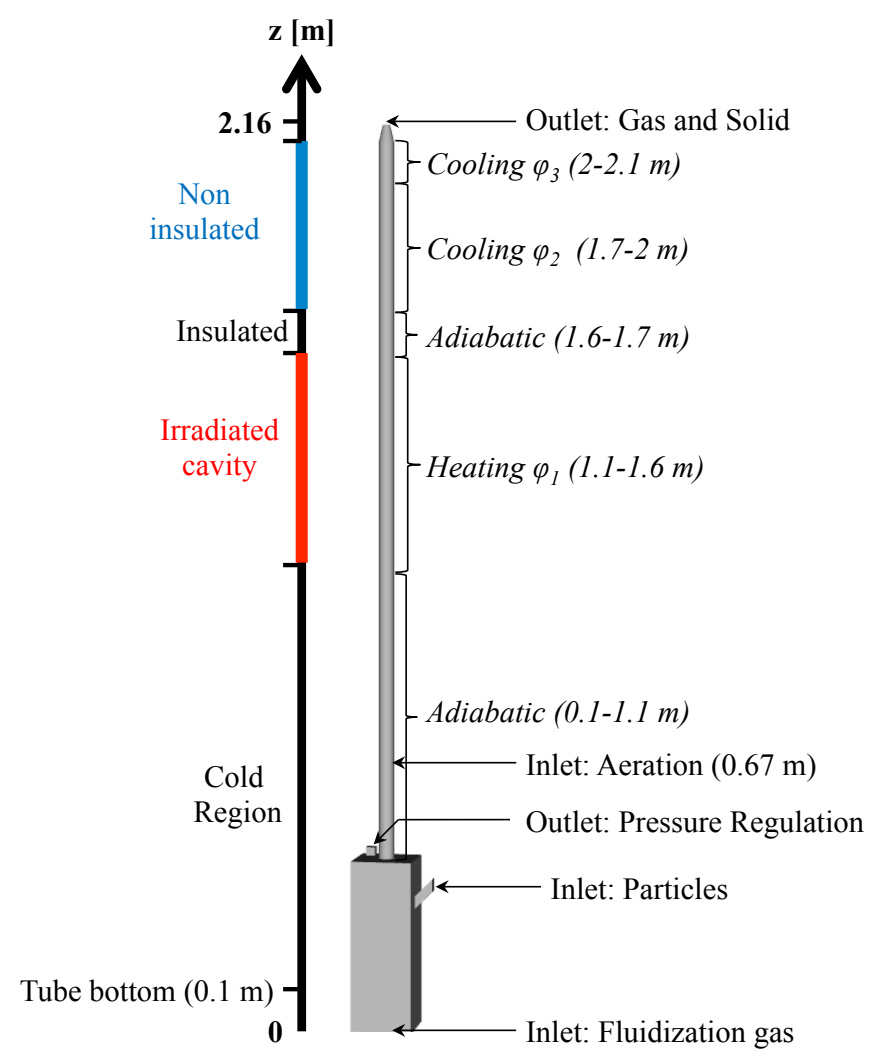

Figure 1: Diagram describing the simulated geometry. 


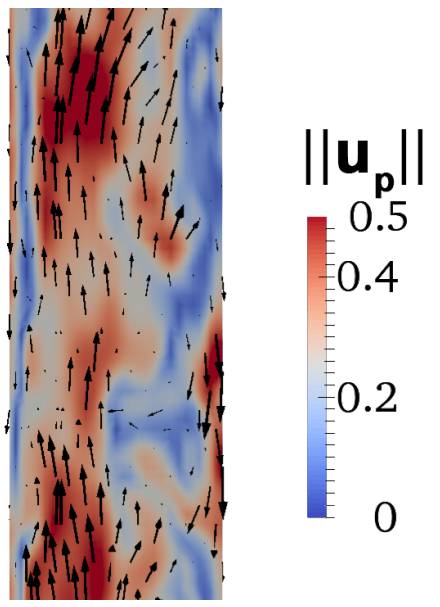

Figure 2: Instantaneous solid velocity vectors and solid velocity magnitude field in background at $\mathrm{t}=720 \mathrm{~s}$, in the tube region between 1.3 and $1.4 \mathrm{~m}$ (Ref case). 


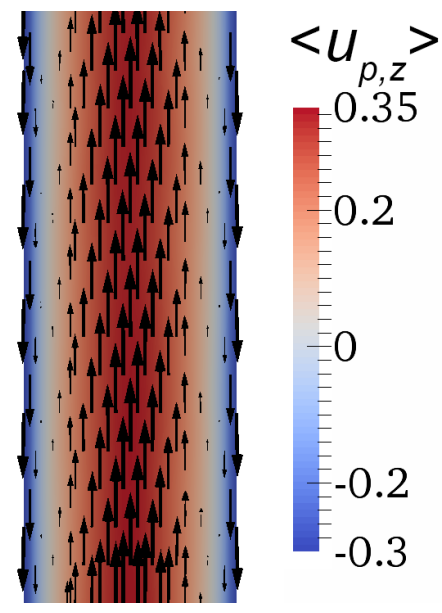

Figure 3: Time-averaged solid velocity vectors and solid vertical velocity field in background, in the tube region between 1.3 and $1.4 \mathrm{~m}$ (Ref case). 


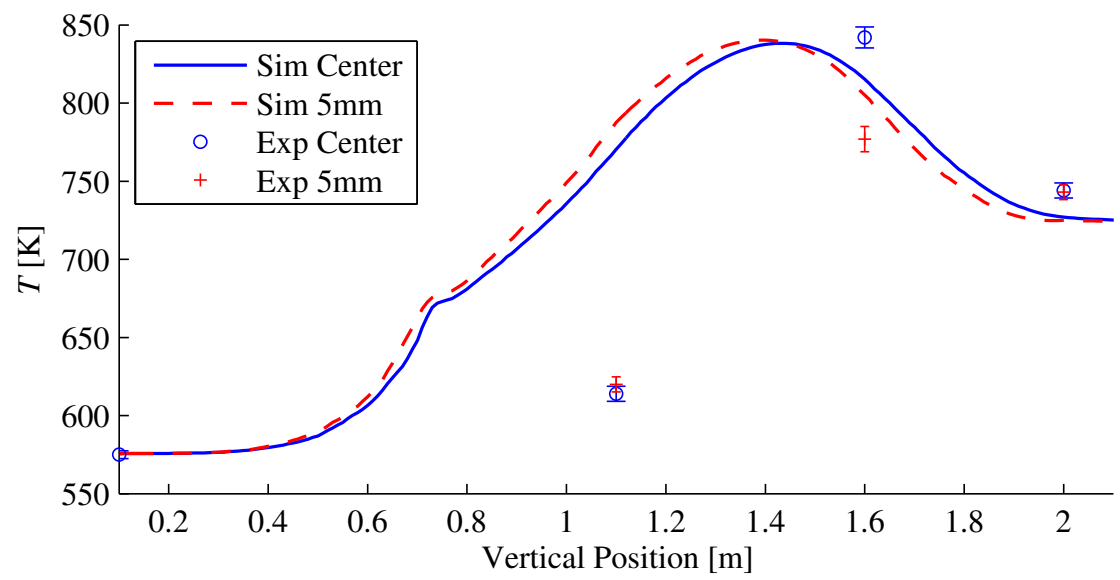

Figure 4: Simulated vertical time-averaged temperature profiles and experimental temperatures at the center of the tube and $5 \mathrm{~mm}$ from the tube wall (Ref case). 


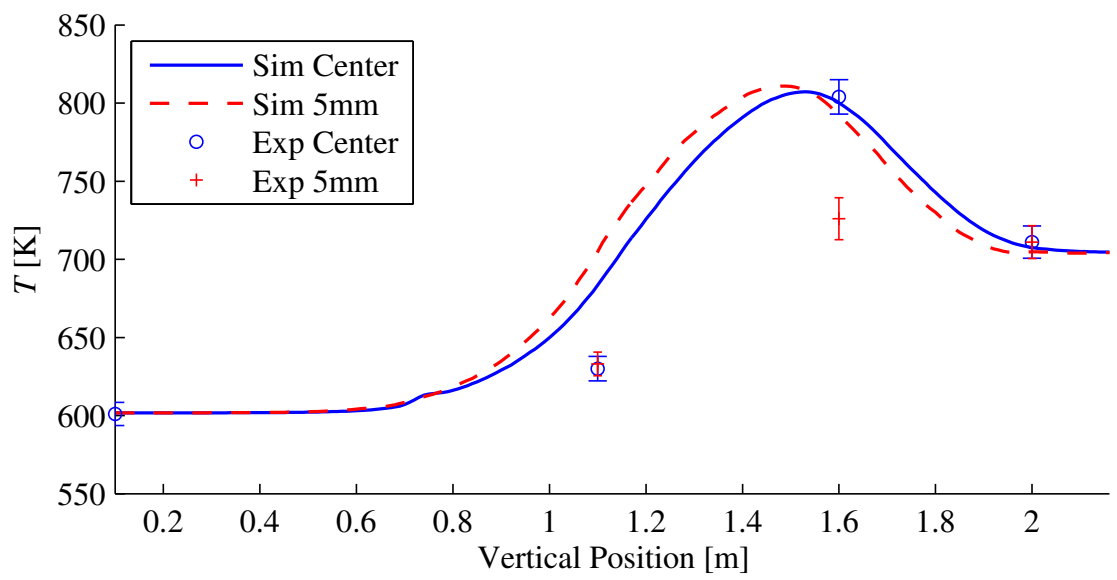

Figure 5: Simulated vertical time-averaged temperature profiles and experimental temperatures at the center of the tube and $5 \mathrm{~mm}$ from the tube wall (HQ case). 


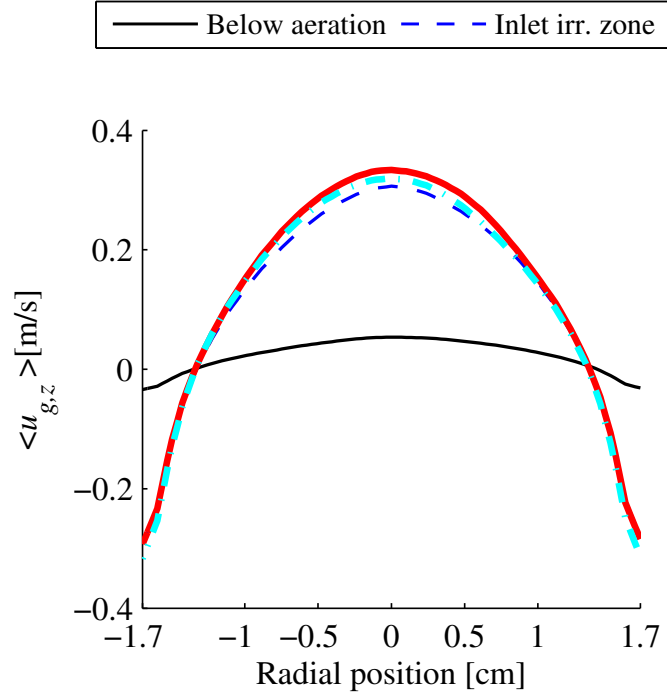

(a) Ref case.

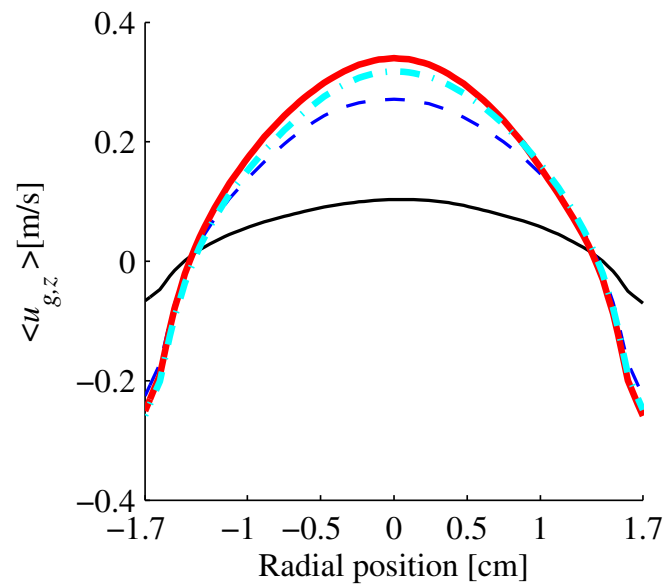

(b) HQ case.

Figure 6: Time-averaged gas vertical velocity radial profiles. 


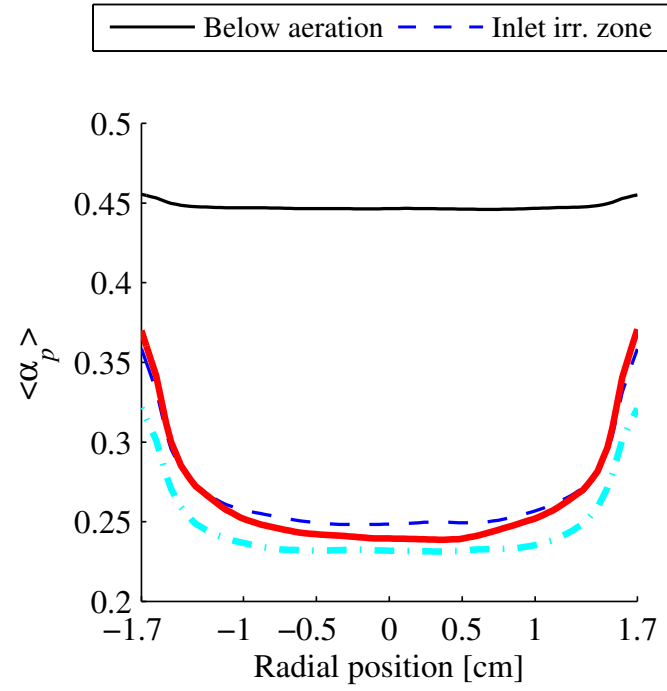

(a) Ref case.

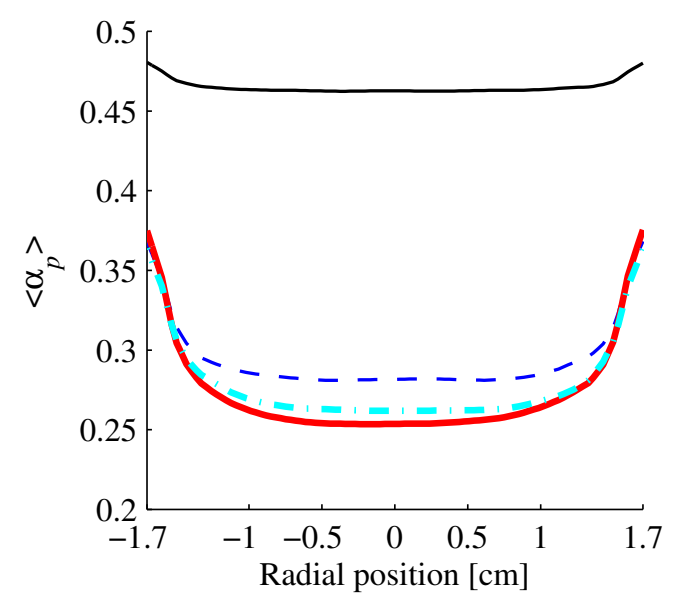

(b) HQ case.

Figure 7: Time-averaged solid volume fraction radial profiles. 
- Below aeration -- - Inlet irr. zone Outlet irr. zone $1=1-$ Above irr. zone

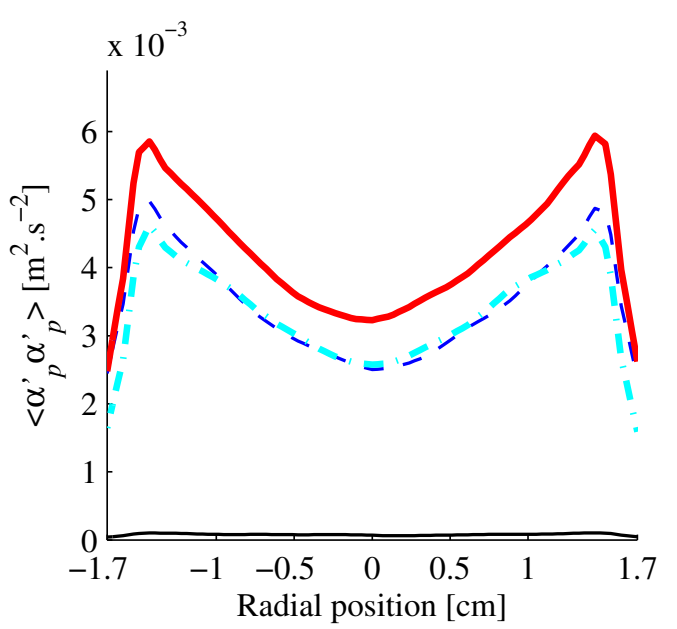

(a) Ref case.

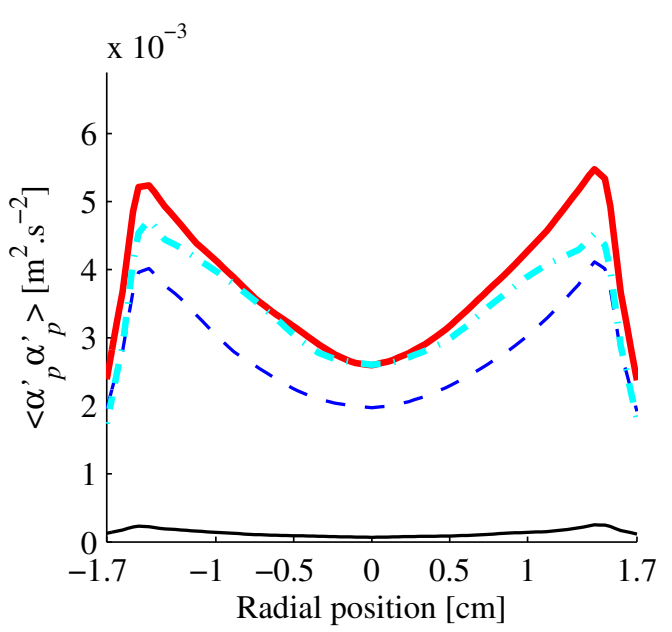

(b) HQ case.

Figure 8: Solid volume fraction time-variance radial profiles. 


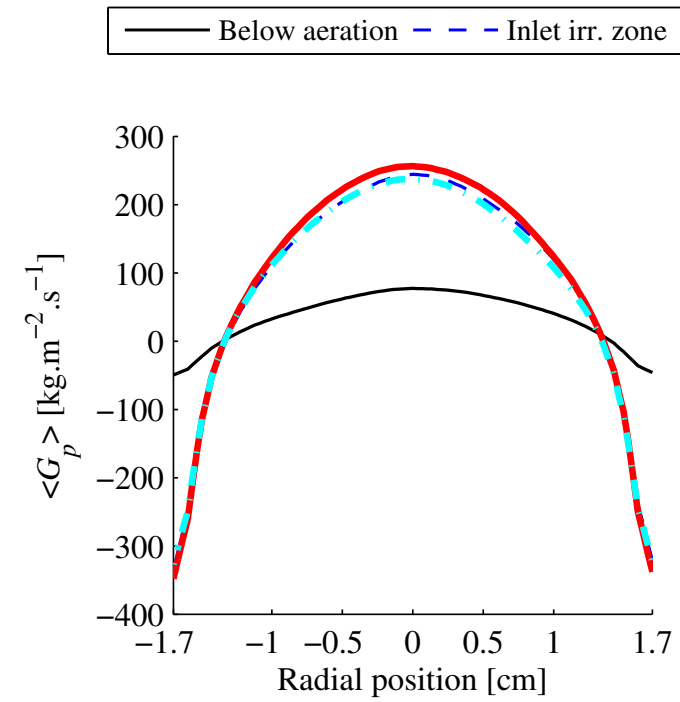

(a) Ref case.

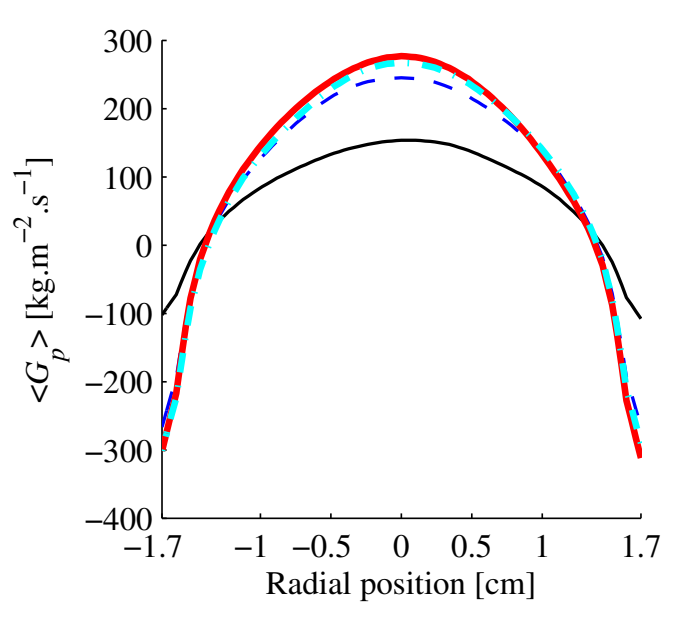

(b) HQ case.

Figure 9: Time-averaged solid mass flux radial profiles 


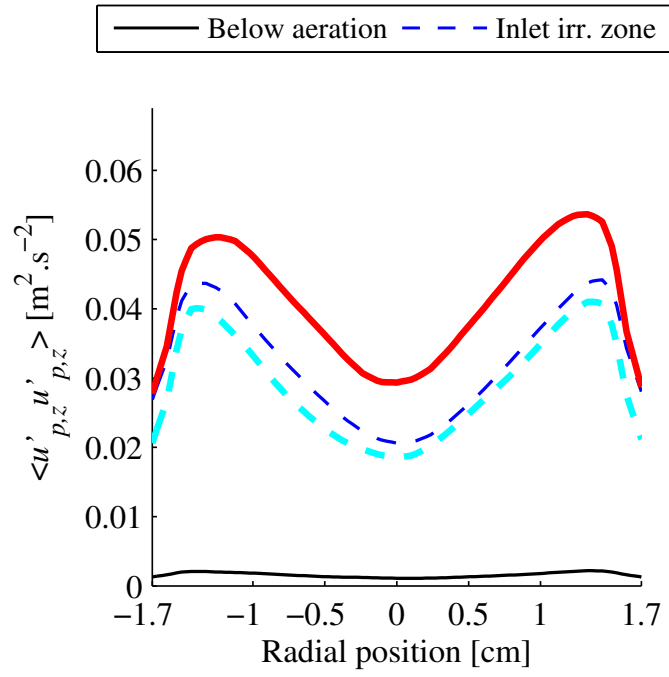

(a) Ref case.

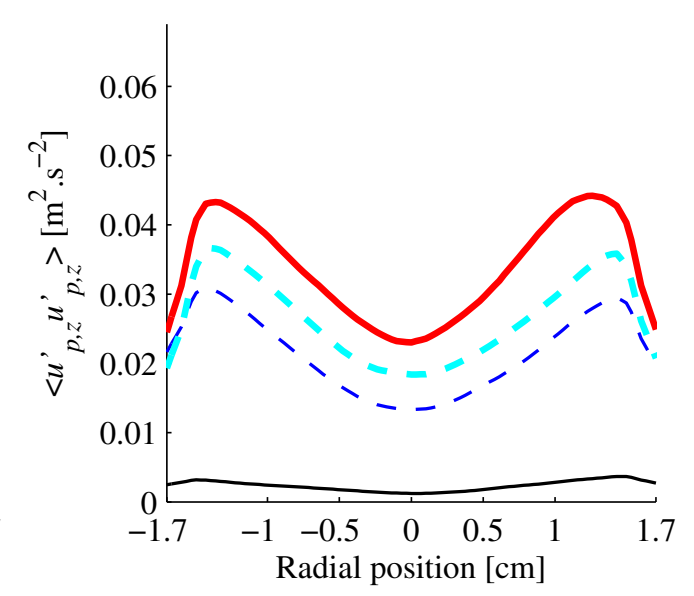

(b) HQ case.

Figure 10: Particle vertical velocity time-variance radial profiles. 
- Below aeration -- - Inlet irr. zone Outlet irr. zone $1=1-$ Above irr. zone

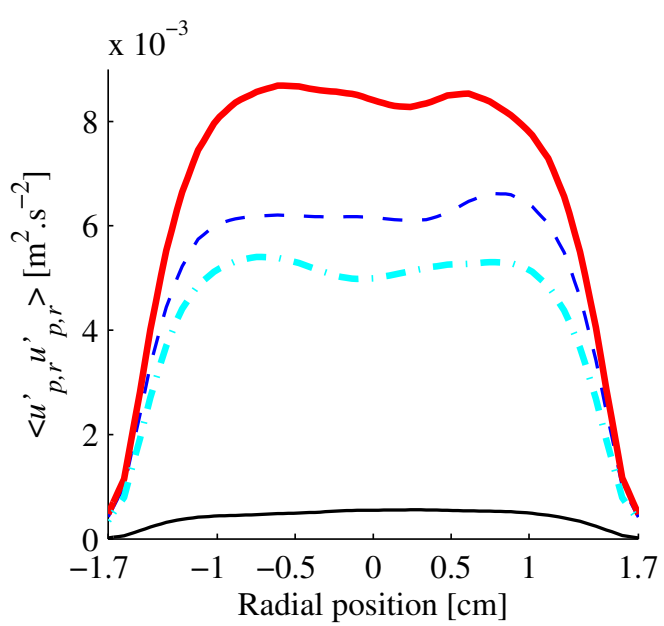

(a) Ref case.

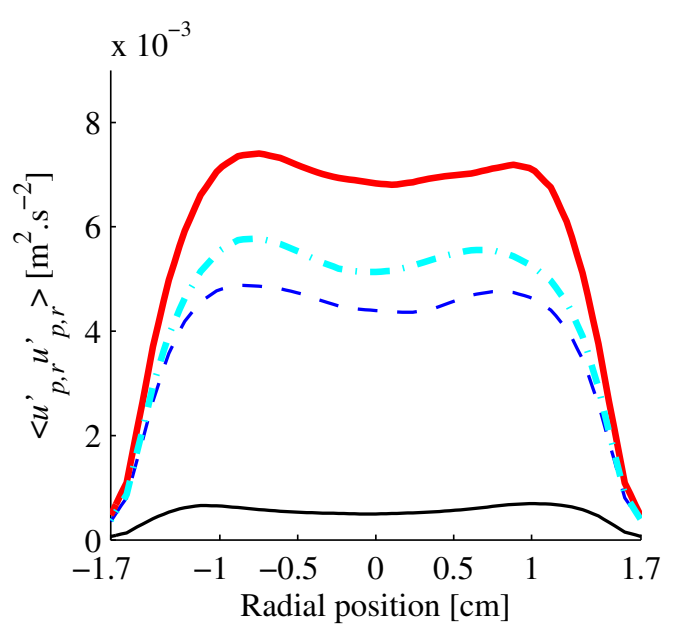

(b) HQ case.

Figure 11: Particle radial velocity time-variance radial profiles. 


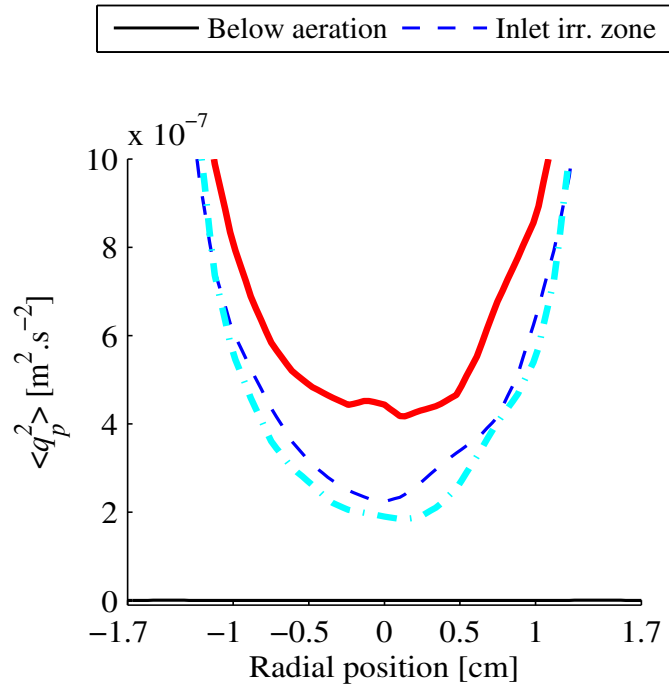

(a) Ref case.

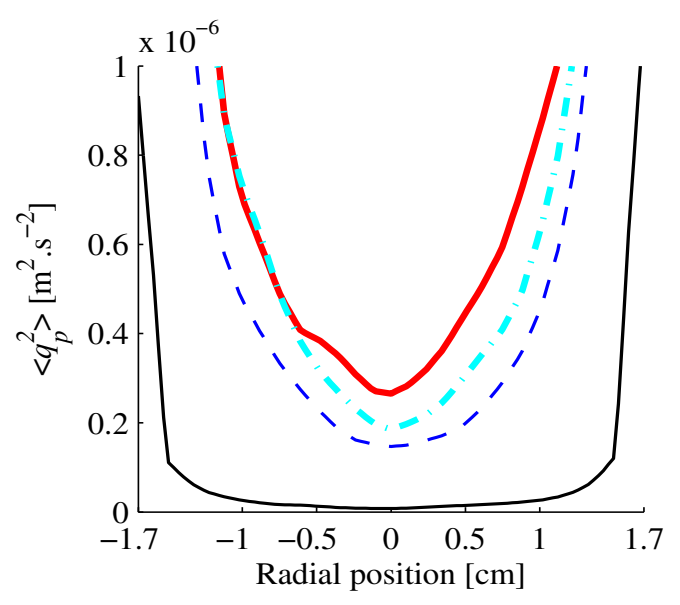

(b) HQ case.

Figure 12: Radial profiles of time-averaged random kinetic energy of particles radial profiles. 


\section{List of Tables}

1 Solid and gas phase properties . . . . . . . . . . . . . 49

2 Boundary conditions ................. . . 50 50

3 Parameters comparison between experiments and simulations . 51 
Table 1: Solid and gas phase properties

\begin{tabular}{|c|c|}
\hline Properties & Values/Equations \\
\hline \multicolumn{2}{|r|}{ SiC particles } \\
\hline Diameter & $d_{p}=40 \mu m$ \\
\hline Density & $\rho_{p}=3210 \mathrm{~kg} / \mathrm{m}^{3}$ \\
\hline $\begin{array}{l}\text { Specific } \\
\text { heat }\end{array}$ & $\begin{array}{l}C_{p, p}=8.564 \times 10^{-16} H_{p}^{3}-1.647 \times 10^{-9} H_{p}^{2}+1.39 \times 10^{-3} H_{p}+ \\
717.5 \text { in }\left[\mathrm{J} \mathrm{kg}^{-1} \cdot \mathrm{K}^{-1}\right]\end{array}$ \\
\hline Temperature & $\begin{array}{l}T_{p}=4.01 \times 10^{-16} H_{p}^{3}-7.35 \times 10^{-10} H_{p}^{2}+1.33 \times 10^{-3} H_{p}+294.2 \\
(6) \text { in }[\mathrm{K}]\end{array}$ \\
\hline \multicolumn{2}{|r|}{ Air } \\
\hline Density & $\begin{array}{l}\rho_{g}=\frac{P}{r T_{g}} \\
\text { in }\left[\mathrm{kg} / \mathrm{m}^{3}\right]\end{array}$ \\
\hline $\begin{array}{l}\text { Specific } \\
\text { heat }\end{array}$ & $\begin{array}{l}C_{p, g}=-1.346 \times 10^{-11} H_{g}^{2}+1.793 \times 10^{-4} H_{g}+1003 \\
\text { in }\left[\mathrm{J} . \mathrm{kg}^{-1} \cdot \mathrm{K}^{-1}\right]\end{array}$ \\
\hline Temperature & $\begin{array}{l}T_{g}=-7.457 \times 10^{-11} H_{g}^{2}+9.931 \times 10^{-4} H_{g}+293.3 \\
\text { in }[\mathrm{K}]\end{array}$ \\
\hline $\begin{array}{l}\text { Dynamic } \\
\text { viscosity }\end{array}$ & $\begin{array}{l}\mu_{g}(T)=\mu_{r}\left(\frac{T_{g}}{T_{r}}\right)^{m} \frac{T_{r}+B}{T_{g}+B} \\
\text { in [Pa.s] with } \mu_{r}=1.716 \times 10^{-5} \text { Pa.s, } T_{r}=273.15 \mathrm{~K}, m= \\
1.54, B=110.4 \mathrm{~K}\end{array}$ \\
\hline $\begin{array}{l}\text { Thermal } \\
\text { diffusivity }\end{array}$ & $\begin{array}{l}K_{g}^{l}=\frac{1}{\rho_{g}}\left[-1.877 \times 10^{-17} H_{g}^{2}+5.878 \times 10^{-11} H_{g}+2.631 \times 10^{-}\right. \\
\text {in }\left[\mathrm{m}^{2} . \mathrm{s}^{-1}\right]\end{array}$ \\
\hline
\end{tabular}


Table 2: Boundary conditions

\begin{tabular}{lllllllc}
\hline Case & $F_{p}$ & $F_{f}$ & $F_{A}$ & $T_{p, i \text { DiFB }}$ & $\varphi_{1}$ & $\varphi_{2}$ & $\varphi_{3}$ \\
& {$[\mathrm{~kg} / \mathrm{h}]$} & {$[\mathrm{kg} / \mathrm{h}]$} & {$[\mathrm{kg} / \mathrm{h}]$} & {$[\mathrm{K}]$} & {$\left[\mathrm{kW} / \mathrm{m}^{2}\right]\left[\mathrm{kW} / \mathrm{m}^{2}\right]\left[\mathrm{kW} / \mathrm{m}^{2}\right]$} \\
\hline Ref & 59.8 & 0.483 & $8.92 \times 10^{-2}$ & 575 & 128.9 & -120.9 & -20 \\
HQ & 147.4 & 0.483 & $8.92 \times 10^{-2}$ & 601 & 189.7 & -172.6 & -25 \\
HT & 32.8 & 0.483 & $1.78 \times 10^{-1}$ & 782 & 107.3 & -159.7 & -17 \\
\hline
\end{tabular}

Ref: medium solid flux-medium temperature, HQ: high solid flux-medium temperature, HT: low solid flux-high temperature, $F_{p}$ : particle mass flow rate, $F_{f}$ : fluidization air mass flow rate, $F_{A}$ : aeration air mass flow rate, $T_{p, i D i F B}$ : DiFB temperature, $\varphi_{1 / 2 / 3}$ : heat flux densities from $1.1 \mathrm{~m}$ to $1.6 \mathrm{~m}$, from $1.7 \mathrm{~m}$ to $2 \mathrm{~m}$ and from $2 \mathrm{~m}$ to $2.1 \mathrm{~m}$, respectively (cf. Figure 1) 
Table 3: Parameters comparison between experiments and simulations

\begin{tabular}{|c|c|c|c|c|c|c|c|c|c|}
\hline \multirow[t]{2}{*}{ Parameter } & \multicolumn{3}{|c|}{ Ref case } & \multicolumn{3}{|c|}{ HQ case } & \multicolumn{3}{|c|}{ HT case } \\
\hline & $\operatorname{Exp}$ & Sim & Error & $\operatorname{Exp}$ & Sim & Error & Exp & Sim & Error \\
\hline$G_{p}\left[\mathrm{~kg} \cdot \mathrm{m}^{-2} \cdot \mathrm{s}^{-1}\right]$ & 18.3 & 18.1 & $-1.1 \%$ & 45.1 & 44.7 & $-0.7 \%$ & 10 & 10.1 & $1 \%$ \\
\hline$\Delta P / L[\mathrm{~Pa} / \mathrm{m}]$ & 8750 & 8767 & $0.2 \%$ & 8880 & 9120 & $2.6 \%$ & 6180 & 4510 & $-27 \%$ \\
\hline$T_{i, \text { center }}[\mathrm{K}]$ & 614 & 770.5 & $25 \%$ & 630 & 684 & $9 \%$ & 872 & 992 & $14 \%$ \\
\hline$T_{o, \text { center }}[\mathrm{K}]$ & 842 & 815.4 & $-3.2 \%$ & 802 & 804 & $0.2 \%$ & 1004 & 951 & $-5.3 \%$ \\
\hline$T_{2 m, \text { center }}[\mathrm{K}]$ & 743 & 727 & $-2.2 \%$ & 711 & 708 & $-0.4 \%$ & 842 & 856 & $1.7 \%$ \\
\hline
\end{tabular}

